\title{
The Conceptual Model on Smart Phone Addiction among Early Childhood
}

\author{
Cheol Park and Ye Rang Park
}

\begin{abstract}
This study examined the antecedents and consequences of children's smart phone addiction. Antecedents of smart phone addiction among children were divided into parental variables and child variables. When parents' education/income/age is higher, dual-income family, the longer parents themselves use smart phones, permissive parenting style, and positive attitudes towards smart phone, children tend to have higher possibility to be addicted to smart phones. Related to child variables, younger children, boys, less siblings, and not attending education institution, predict smart phone addiction. Children with smart phone addiction show problems in mental and physical development. The implications and further study are suggested based on the conceptual model.
\end{abstract}

Index Terms - Smart phone, addiction, child, parents, family.

\section{INTRODUCTION}

Recently, smart phone is rapidly spreading among people. There are about 32,730,000 smart phone users in Korea, and more than half of the all population is using smart phones daily. Due to the introduction of cheap phones which are 50\% cheaper than the original price of smart phones, more and more people started to use smart phones. Smart phone has become indispensable tool in everyday life and mobile tool that everyone can easily approach. Especially, smart phones are not only for the adults, but also available for young children to approach and use. Children can easily contact smart phones to use and they use them as toys.

Because parents busy working easily provide their children with smart phones, young children are using smart phones more often, which sometimes leads to smart phone addiction. Due to '2012 The Survey of Internet Addiction' by National Information Society Agency, among internet users from age 5 to 49 , the rate of internet addiction is $7.2 \%$, and the number of people addicted to internet are 223,000 in Korea. According to age, teenage addiction rate, $10.7 \%$, was the highest. Twenties showed $9 \%$, and young children from 5 to 9 showed $7.3 \%$.

However, noticeable change is that addiction rate of young children before school has increased from 3.6\%, last year, to $4.3 \%$. As a result, negative physical and mental effects occur according to research. Smart phone addiction among young children degrades function of right brain by brain balance

Manuscript received July 28, 2013; revised September 20, 2013. This work was supported in part by SSK 2011 of Korea Research Foundation (NRF-2011-330-B00096).

C. Park is with Division of Business Administration, Korea University, Sejong-ro 2511, Sejong 339-700, South Korea (e-mail: cpark@ korea.ac.kr).

Y. R. Park is with Department of Child Psychology and Education, Sungkyunkwan University, Sungkyunkwan-ro 25-2, Seoul 110-745, South Korea (e-mail:rangpark92@naver.com). according to brain wave test. Furthermore, smart phone does not fit early childhood development stage because it is a very passive tool which you just sit down and absorb the knowledge. The function of frontal lobe in brain which relates to the ability to think, judge, and concentrate is damaged, so that normal brain development is hindered.

Researchers have pointed out that the brain structure becomes like 'popcorn brain', which is dull to reality. There are research results that show smart phones cause Attention Deficit and Hyperactivity Disorder (ADHD). Similarly, according to a recent research about smart phone addiction among adolescents by National Youth Policy Institute, one out of three is at risk of addiction nationally. The same result is found in '2012 Survey of Internet Addiction' by Ministry of Science, ICT and Future Planning, which shows the rate of smart phone addiction among children reaching twice of adults'.

Due to the advent of educational applications, according to game auditing committee's research, the first average age to start playing games has become lower from 20095 to 2012 4.8. Average number of playing games in a week is 3.7 from age 3 to 9 and 3 from age 9 to 18. Also in physical aspect, overuse of smart phone can cause VDT (Visual Display Terminal) which makes young children to wear glasses.

Amount of physical exercise has also decreased which interferes with physical growth and development. Mentally, children with smart phone or game addiction are deprived of the ability to sympathize with other children and become aggressive which make them difficult to make friends. These negative results imply that IT tools should not be used as means to take care of children.

Therefore, in this study, conceptual framework comprised of antecedents and consequences affecting smart phone addiction among early childhood will be proposed.

\section{LITERATURE REVIEWS}

There are several studies about smart phone addiction among adults [1]-[3]. However, researches related to studies regarding smart phone addiction among early childhood are hardly found both domestically and abroad [4]. Because these phenomena are recently spread, there are some articles about it [5], [6], but few academic reports are reported. However, similarly, several researches related to internet addiction among children [7]-[21] or researches related to game addiction [14], [22]-[26] were found quite a lot.

Jung and Ha has studied about the effects of stress and emotional expression that affect smart phone addiction among elementary school students [4]. In this research, they found out that the higher the stress related to studying and the 
negative emotional expression was, the higher the smart phone addiction rate was. Kang and Park developed smart phone addiction rating scale and verified it [22]. As a result, smart phone addiction and depression, anxiety, impulsiveness, and lack of control showed significant relationship. Lee said that the factor that affects smart phone addiction is habitual overuse due to smart phone's convenience and playfulness, which leads to life problems [3].

Therefore, this research will divide the antecedents of smart phone addiction among early childhood into parental variables and child variables, and look at consequences that smart phone addiction has on children's mental and physical development.

\section{A PROPOSED MODEL}

Fig. 1 shows our proposed model on smart phone addiction among early childhood.

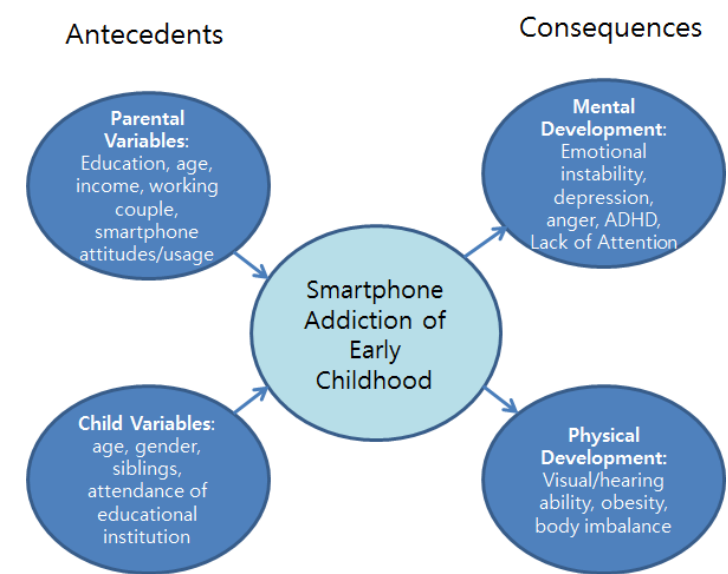

Fig. 1. A model on Smartphone addiction of early childhood

\section{A. Antecedents}

\section{1) Parental variables}

Just as family's effect on children's game addiction is significant [22], family's effect on children's smart phone addiction is also substantial. Parental variables that affect smart phone addiction are parents' education, age, income, whether parents are working together, raising attitude, attitudes towards smart phone, and addiction tendency.

In many studies, the lower the parents' income and education [18] were, the higher the possibility of children having problems [27] was. When parents' education is lower, knowledge about seriousness of smart phone addiction is also lower, so it is easy to give smart phone to their children, resulting in higher smart phone addiction rate. Parents with poor income cannot afford expensive smart phone, so their children's smart phone addiction rate might be low. However, adults' smart phone adoption rate has reached almost $90 \%$, and non-adoption group is limited to old-aged group, so almost all low income parents have smart phones. They lack resources to raise their children, so they easily let their children use smart phones same as game addiction of children [26]. Therefore, the lower the parents' income is, the higher their children's smart phone addiction rate is.

Smart phone is a device which young people easily use and adopt pervasively. Younger parents tend to have more generous adoption attitudes about smart phone, and higher usage frequency. As a result, their children have higher chance of contact and using smart phones, therefore having higher smart phone addiction rate like internet addiction of children [7].

Children from dual-income family have longer time alone and because of lack of parent's amount of time to take care of their children; they are generous about the requirements of their children [11]. Therefore, they easily let their children use smart phones, resulting in higher smart phone addiction rate.

Types of parenting can be divided into authoritarian, permissive, and responsive [28]. Authoritarian is one-way and rigorous way of raising children, strictly controlling their children. Permissive is full of affection, inconsistent, and laissez faire. On the other hand, responsive is respecting children's autonomy, being consistent. Children from authoritarian parents lack their own goals or judgments, exclusive and aggressive. Children from permissive parents are impulsive, selfish, stubborn, and hysteric. Children from responsive parents have clear goals and decision of their own, self-regulated and having high self-trust, they are likely to have positive and harmonious interpersonal relationships. Therefore, permissive parents are most likely to have children with higher smart phone addiction rate [27].

In addition, parents' attitudes towards smart phone or usage behaviors are likely to have influenced children's smart phone addiction rate same as internet addiction of children [9]. When parents have more positive attitudes towards smart phone, they let their children use smart phone more easily, resulting in higher rate of smart phone addiction. Furthermore, if parents themselves are heavy users of smart phone or addicted to it, their children have higher chance to be exposed to smart phones, resulting in higher smart phone addiction rate.

\section{2) Child variables}

Child variables affecting child smart phone addiction are child's age, gender, number of siblings, and whether they attend education institutions or not.

The lower child's age is, mental development is incomplete and easily immersed, having higher possibility of smart phone addiction [10]. In addition, boys tend to have more curiosity about tools and needs for trial. Also, boys tend to be more distractive and lack of self-control [14], so they have higher possibility of addiction to smart phone. While higher number of siblings means higher possibility of interacting with other people, lower number of siblings means more time spending alone, resulting in higher possibility of addiction to digital tools like smart phones [15]. In addition, when a child attends education institutions like preschool or kindergarten, they are likely to be under teacher's control and have more time to interact with peers, resulting in lower smart phone addiction rate. On the other hand, children not attending any education institutions have more time alone at home and because of lack of parents' resources, they have higher possibility of smart phone addiction.

\section{B. Consequences}

\section{1) Mental development}

Just as children's excessive use of computer have negative 
effects on them [7], children with higher smart phone addiction rate of are likely to have problems with mental development such as emotional instability, depression, Attention Deficit Hyperactivity Disorder(ADHD), anger, and lack of attention [1], [4].

Because smart phones provide sensible and instant stimuli through visual sense and hearing sense, overuse of smart phones is likely to make children who are mentally premature, unstable [13], [26]. Smart phone itself is very playful and immersive [3], so when parents do not let them use it, children have higher chance of being depressed [9]. Furthermore, it causes mental immaturity like aggressiveness and lack of attention [26]. Smart phone addiction, similar to internet and game addiction, also bring results such as children's lack of attention and self-control [19], [21].

\section{2) Physical development}

Higher smart phone addiction rate predicts problems in physical development such as impairments in visual/hearing senses, obesity, body imbalance same as game addiction of children [14], [22], [25], [26]. When you look at the screen light continually, it is bad for eye health of adults, but children are likely to have more severe impairment in visual sense. Also, when you use smart phone for a long time with earphones, bad effects on hearing sense are expected. When you are addicted to smart phones, you have lower chance of interacting with other people [25], and decrease in physical activities will increase the possibility to be obese [3]. On top of that, operating small device with your hands for a long time might result in body imbalance. Children are incomplete in physical development yet, so overuse of smart phones will cause negative effects on children's physical development in many aspects.

\section{CONCLUSION}

This study examined the antecedents and consequences of children's smart phone addiction. Children are have not reached the age to make rational decisions yet, so they can easily be addicted to smart phones. When they easily use parents' smart phones as their toys, and also parents use them as tools to easily take care of their children, smart phone addiction among children is likely to occur.

Antecedents of smart phone addiction among children were divided into parental variables and child variables. When parents' education/income/age are higher, dual-income family, the longer parents themselves use smart phones, permissive parenting style, and positive attitudes towards smart phone, children tend to have higher possibility to be addicted to smart phones. Related to child variables, younger children, boys, children with less siblings, and not attending education institution, predict smart phone addiction.

Children with smart phone addiction show problems in mental and physical development. In other words, a child addicted to smart phone has higher possibility of having problems in mental development such as emotional instability, attention deficit, depression, anger, and lack of control. Also, physical problems such as impairments in visual and hearing senses, obesity, body imbalance, and lack of brain development are found.
Smart phone addiction among children is likely to be continuous throughout the life time, and because of this, there is big personal and social loss. So, efforts of parents and society to prevent the addiction are needed.

First, parents should strive to spend more time with their children. Parents should realize the strong influence of smart phones on their children and it is important not to easily give smart phones to children. It is critical to understand that a convenience of a moment can cause serious results of children's smart phone addiction. Because children have weak control of themselves, they are in need of parents' control. Especially when parents themselves have generous attitudes towards smart phones, dual-income family, and permissive style of parenting, special attention is needed.

In addition, efforts of the society are required. Education institutions such as kindergarten and preschool should teach children not to overuse smart phones. Also, phone companies and application producers should develop techniques to limit the approach in order to prevent children from using smart phone too much or addicted to it.

Smart phone is surely a good device which made our live rich. However, this tool can be a threat to our children, the future of humanity. Parents and the society should strive to minimize the side effects of this without cease, because children are the most valuable future resources that cannot be replaced with anything else.

This research has only proposed research model through literature reviews. In further research, verifying the contents of the proposed model through empirical study is needed.

\section{REFERENCES}

[1] H. Y. Kang and C. H. Park, "Development and validation of the smartphone addiction inventory," Korean Journal of Psychology: General, vol. 31, no. 2, pp. 563-580, 2012.

[2] J. Kim and H. M. Paul, "The role of internet user characteristics and motives in explaining three dimensions of internet addiction," Journal of Computer-Mediated Communication, vol. 14, pp. 988-1015, 2009.

[3] K.-Y. Lee, "The study of factors in affecting the user's addictive behavior in using the smart phone applications," Korean Journal of Business Education, vol. 27, no. 5, pp. 183-208, 2012.

[4] J. Y. Jung and J. H. Ha, "The effects of general stress and emotional expression on upper grades of elementary school students' smart phone addiction," Journal of Family and Counseling, vol. 3, no. 1, pp. 61-77, 2013.

[5] B.-S. Kim. (June 30, 2013). Solutions to children with 'ADHD' due to smartphone addiction. Asia Economics Newspaper. [Online]. Available:

http://view.asiae.co.kr/news/view.htm?idxno=2013063012301303336 \&nvr=Y)

[6] SBS News. (2013.07.16). [Scene 21] Smartphone becomes poison. [Online]. Available: http://news.sbs.co.kr/section_news/news_read.jsp?news_id=N100188 6661

[7] A. Ming, "How computer and Internet use influences mental health: A five-wave latent growth model," Asian Journal of Communication, vol. 23, no. 2, pp. 175-190, 2013.

[8] K. W. Beard and E. M. Wolf, "Modification in the proposed diagnostic criteria for Internet addiction," Cyberpsychology and Behavior, vol. 4, pp. 377-383, 2001.

[9] L. Bonetti, M. A. Campbell, and L. Gilmore, "The relationship of loneliness and social anxiety with children's and adolescents' online communication," Cyberpsychology, Behavior, and Social Networking, vol. 13, no. 3, pp. 279-285, 2010.

[10] Y. Cho and H. Lee, "A study on a model for Internet addiction of adolescents," Journal of Korean Acad Nurs, vol. 34, no. 1, pp. 102-110, 2004. 
[11] C. Chou and M-C. Hsiao, "Internet addiction, usage, gratification, and pleasure experience: The Taiwan college students' case," Computers and Education, vol. 35, no. 1, pp. 65-80, 2000.

[12] J. H. Ha, H. J. Yoo, I. H. Cho, B. Chin, D. Shin, and J. H. Kim, "Psychiatric comorbidity assessed in Korean children and adolescents who screen positive for Internet addiction," Journal of Clin Psychiatry, vol. 67 , no. 5, pp. 821-826, 2006.

[13] K. S. Jang, S. Y. Hwang, and J. Y. Choi, "Internet addiction and psychiatric symptoms among Korean adolescents," Journal of School Health, vol. 78, pp. 165-171, 2008.

[14] C. H. Ko, J. Y. Yen, C. C. Chen, S. H. Chen, and C. F. Yen, "Gender differences and related factors affecting online gaming addiction among Taiwanese adolescents," Journal of Nerv Ment Dis, vol. 193, no. 4, pp. 273-277, 2005.

[15] L. Leung, "Stressful life events, motives for Internet use, and social support among digital kids," Cyber Psychology \& Behavior, vol. 10, no. 2, pp. 204-214, 2007.

[16] S. S. J. Lin and C. C. Tsai, "Internet addiction among high scholars in Taiwan," Paper presented at the annual meeting of the American Psychological Association, Boston, MA, 1999.

[17] K. Nalwa and A. P. Anand, "Internet addiction in students: A cause of concern," Cyber Psychology \& Behavior, vol. 6, no. 6, pp. 653-656, 2003.

[18] W. O. Oh, "Patterns of the Internet usage and related factors with Internet addiction among middle school students," Journal of Korean SocMatern Child Health, vol. 9, no. 1, pp. 33-49, 2005.

[19] C. K. Yang, "Socio-psychiatric characteristics of adolescents who use computers to excess," Acta Psychiatr Scand, vol. 104, no. 3, pp. 217-222, 2001

[20] H. J. Yoo, S. C. Cho, J. Ha, S. K. Yune, S. J. Kim, J. C. Hwang, S. Ain, and Y. H. Lyoo, "Attention deficit hyperactivity symtoms and Internet addiction," Psychiatry and Clinical Neurosciences, vol. 58, pp. 487-494, 2004

[21] H. J. Yoo, C. S. Lee, Y. H. Kang, and J. W. Sohn, "The correlations between internet addiction and attention deficit-hyperactivity/impulsivity symptoms in Korean high school students," Annual Meeting of Korean Neuropsychiatric Association, Seoul, Korea, 2002.

[22] J-W. Kang, S-J. Jang, and S.-O. Kim, "A study on the effect of variables of young children and family on internet game addiction inclination for young children," Journal of Media for Childhood Research, vol. 10, no. 3, pp. 205-224, 2011.

[23] K. Kwak and S. Kang, "The case study of the preoccupation with video games in children (I). Korean," Journal of Human Dev., vol. 4, pp. $1-18,1998$.

[24] E.-K. Lee, "The computer game addiction of early childhood, Working Paper, Myungji University, 2008.

[25] S.-H. Lee, "The study of aggression and change to social relationship on early childhood's computer game addiction," Korean Journal of Early Childhood Education Research, vol. 14, no. 1, pp. 185-202, 2010.

[26] M.-Y. Seo and E.-M. Lim, "Infants' and low-grade elementary students' internet game addiction tendency and the relationship between game addiction tendency and personality characteristics," The Journal of Child Education, vol. 19, no. 4, pp. 163-175, 2010.

[27] P. K. Kerig and C. Wenar, Developmental psychopathology: From infancy through adolescence, McGraw Hill, 2006.

[28] D. Baumrind, "The influence of parenting style on adolescent competence and substance use," The Journal of Early Adolescence, vol. 11, no. 1, pp. 56-95, 1991.

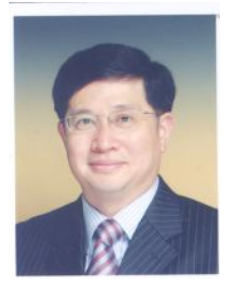

C. Park is a professor of e-marketing at School of Business Administration, Korea University. He received his master and Ph.D. degree in Management from Seoul National University in Korea. His research interests include marketing and consumer behaviors in digital environments. He published papers in Journal of Business Research, Journal of Interactive Marketing, Industrial Marketing Management, International Marketing Review, International Journal of Mobile Communications, and etc.

Y. R. Park is an intern teacher of Banpo Kindergarten, Seoul. She is studying Child Psychology and Education at Sungkyunkwan University in Korea. She is interested in development psychology of early childhood. 